
PREFERENCE: AN RCT COMPARING REFILLABLE CYLINDERS (HOMEFILLTM) WITH USUAL AMBULATORY DEVICE

doi:10.1136/thoraxjnl-2012-202678.187

'J Turnbull, 'L McDonnell, 'L Osman, ${ }^{2} \mathrm{~J}$ Bott, ${ }^{3} \mathrm{~T}$ Prevost, ${ }^{1} \mathrm{AC}$ Davidson. 'Guys and St Thomas' NHS Foundation Trust, London, UK; '2Surrey Community Health, Chertsey, UK: ${ }^{3}$ Department of Public Health Sciences, London, UK

Introduction The benefit of ambulatory oxygen $(\mathrm{AO})$ in patients with hypoxaemia on exercise remains contentious. Often $\mathrm{AO}$ is not used in the way the prescribers envisage. Device suitability or poor understanding about the benefits of $\mathrm{AO}$ may mean patients remain hypoxic on activity and/or avoid exercise.

Objective To assess patients activity and preference using Homefill $^{\mathrm{TM}}$ versus usual $\mathrm{AO}$ device in a mixed population of patients with exercise hypoxaemia and/or LTOT. Homefill ${ }^{\mathrm{TM}}$ allows patient refill of oxygen cylinders (1.9 L) as needed using a compressor.

Methods Inclusion criteria included current use of $\mathrm{AO}$ and stable physical condition. AO prescription was optimised for each device. Patients were randomised to usual $\mathrm{AO}$ then Homefill ${ }^{\mathrm{TM}}$ for 6 wks or vice versa. Tri-axial activity monitors were used during the last week. Patient preference was identified by questionnaire. Weekly calls encouraging activity and $\mathrm{AO}$ use were made. If patients suffered an inter-current illness, the trial arm was extended by 2 wks; those with $>1$ illness were withdrawn. Power calculation indicated a sample of 40 subjects was required to detect a difference of 1,000 domestic activity counts at a 5\% significance level with $80 \%$ power. Results 70 patients met the inclusion criteria and 40 enrolled. Mean age 66 yrs, 17 males, 70\% had COPD with median $\mathrm{FEV}_{1} 41 \%$ predicted (range $27-71 \%$ ), restrictive median FVC $70 \%$ predicted. 29 complete data sets were collected. There were 9 episodes of AECOPD. Fifteen patients required the highest $0_{2}$ pulsed setting on Homefill ${ }^{\mathrm{TM}}$ There was no statistically significant difference in mean daily activity counts when using Homefill ${ }^{\mathrm{TM}}$ compared to usual AO. A decline in activity counts was observed in both cohorts during the second period. Eighteen patients elected to keep Homefill ${ }^{\mathrm{TM}}$ of whom 11 previously used LOX as their usual AO.
Conclusions Homefill was equivalent to usual provision of $\mathrm{AO}$ and was preferred by the majority. Disappointingly, regular phone encouragement failed to increase activity levels. Activity levels were very low and highly variable reflecting advanced disease/deconditioning. Implications for Practise Patient use and preference of $\mathrm{AO}$ device includes non physiological aspects. AO maybe best targeted at patients before exercise tolerance is severely limited.

\section{P47 POST-OPERATIVE OXYGEN SATURATION, PRESCRIBING \& ADMINISTRATION IN PATIENTS UNDERGOING ELECTIVE ORTHOPAEDIC SURGERY}

doi:10.1136/thoraxjnl-2012-202678.188

AM Hogan, E Anand, MJ Oddy, J Welch, H Booth. University College London Hospital, London, UK

Introduction There is increasing interest in maximising perioperative care of surgical patients, including response to oxygen desaturation which may occur in association with anaesthesia, analgesic/ sedative drugs, and/or indicate pathology. There is thus potentially great importance in understanding the incidence and profile of oxygen desaturation in the post-operative patient, and documenting our response to it.

Methods We recorded sequential $\mathrm{SpO}_{2}$ values and oxygen prescription/administration from the charts of 65 patients (mean age 56.5 years (SD 20.2), BMI 29.6 (10.5), 38 Females) admitted to University College London Hospital for elective orthopaedic surgery, starting at point of transfer from recovery room to ward. Nine were current smokers, one patient had COPD, and eight had possible sleep apnoea. None used home oxygen or CPAP and all were normoxic pre-operatively.

Results One-third (30.8\%; 20/65) of patients experienced an isolated, minor desaturation event (Figure 1): mean minimum $\mathrm{SpO}_{2}$ 91.9\% (SD 2.2). 'Desaturators' were older $(P=0.038)$ but not 'sicker' compared to those who remained normoxic, determined by smoking status and ASA grade, and by post-operative rate of chest $\mathrm{x}$-ray request, blood transfusion, and antibiotic requirement. Thus, the majority of desaturations were minor and of limited clinical

Figure 1. Individual profiles of sequential $\mathrm{SpO}_{2}$ values. The grey shaded boxes represent target oxygen saturation ranges according to British Thoracic Society guidelines (94-98\% $\mathrm{SpO}_{2}$; alternatively, $88-92 \% \mathrm{SpO}_{2}$ is preferable in some patients with respiratory disease). Each dot represents a $\mathrm{SpO}_{2}$ value and connecting lines connect values in individual patients.

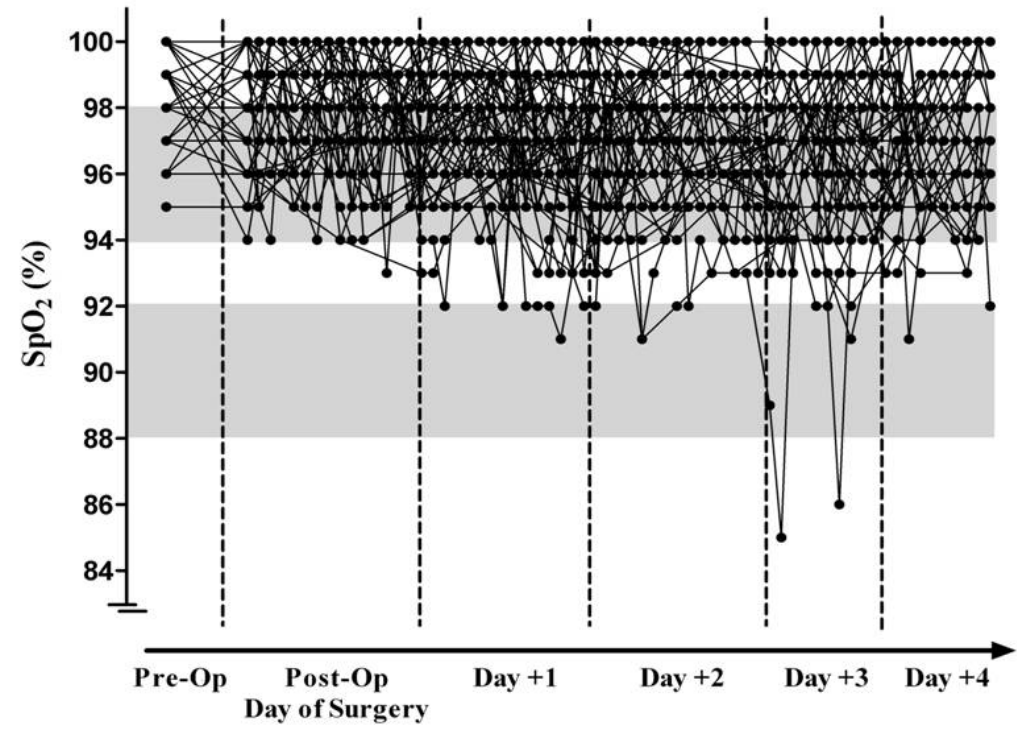

Abstract P47 Figure 1 
significance; in a few cases perhaps representing spurious values. Recurrent ( $>/=3$ desaturations/24 hours) with/without more serious desaturations $\left(<90 \% \mathrm{SpO}_{2}\right)$ occurred in $6.2 \%(4 / 65)$. Oxygen was prescribed for only one-third of patients $(35.4 \%$; $23 / 65)$, but was administered to three-quarters $(75.4 \% ; 49 / 65)$ typically as a gradual 'down-titration' of high-flows given in recovery rather than in response to desaturation. Some patients remained on oxygen despite sequential $\mathrm{SpO}_{2}$ values of $100 \%$. Strong opiates were frequently prescribed $(93.8 \% ; 61 / 65)$, sometimes with night sedation (9.2\%; 6.65).

Comment British Thoracic Society national guidelines encourage oxygen administration titrated to $\mathrm{SpO}_{2}$, but we show that this aim may not currently be fully realized in surgical patients, perhaps partly due to lack of routine oxygen prescribing. Encouragement of early oxygen prescribing by surgeons and anaethetists, who already routinely prescribe thrombo-prophylaxis, prophylactic antibiotics and analgesia, might help to ensure that patients are set-up for better matching of oxygen administration to need for the duration of their post-operative recovery.

\section{Diagnosis and management of TB}

\section{P48 VITAMIN D LEVELS ARE NOT ASSOCIATED WITH MARKERS OF INFLAMMATION AND DISEASE SEVERITY IN ACUTE TUBERCULOSIS}

doi:10.1136/thoraxinl-2012-202678.189

FM Perrin, E Togun, S Stephens, 0 Sewo, RD Barker. Kings College Hospital, Kings Health Partners, London, United Kingdom

Background There is considerable evidence that patients with clinical tuberculosis in the UK have low levels of circulating Vitamin $D^{1}$. It has been suggested that acquired Vitamin D deficiency impairs immune function and therefore allows patients to transform from latent to clinical tuberculosis. Sceptics have suggested that the low Vitamin $\mathrm{D}$ levels seen in clinical tuberculosis are a result of disease activity rather than a cause of it. We examined whether Vitamin D levels were associated with blood markers of inflammation and disease severity inpatients newly diagnosed with tuberculosis.
Methods All patients diagnosed with tuberculosis at an inner London teaching hospital since 2000 were eligible for inclusion in the study although systematic measurement of Vitamin D levels has only been attempted in recent years. Vitamin D levels were classified as deficient $<=10 \mathrm{ng} / \mathrm{ml}$, insufficient $>10$ to $<30 \mathrm{ng} / \mathrm{ml}$ and sufficient $>=30 \mathrm{ng} / \mathrm{ml}^{2}$ The date treatment started was recorded. The first blood measurement of Vitamin D, Haemoglobin, Neutrophil count, c-reactive protein(CRP), erythrocyte sedimentation rate (ESR) and albumin taken within two weeks of treatment starting were recorded. All variables were assessed for correlation with one another using Pearson's correlation coefficient in SPSS.

Results One thousand four hundred and twenty two patients were identified of whom 262 had a measurement of Vitamin D. 151 (58\%) were Vitamin D deficient and a further 96 (37\%), Vitamin D insufficient. Data availability ranged from 1266 patients with a serum albumin to 222 patients with an ESR. Blood markers of disease severity and inflammation were significantly correlated but Vitamin D levels did not correlate with any of the other variables.

Discussion These data do not support the hypothesis that low Vitamin Dlevels in acute tuberculosis are a result of disease activity or severity. It would be reasonable to consider the prevention of Vitamin D deficiency as a means to reduce the conversion of latent to clinical tuberculosis.

\section{References}

1. Sita-Lumsden A, Lapthorn G, Swaminathan R, Milburn HJ. Reactivation of tuberculosis and vitamin $\mathrm{D}$ deficiency: the contribution of diet and exposure to sunlight. Thorax 2007; 62(11):1003-7.

2. Rosen CJ. Vitamin D Insufficiency. New EnglandJournal of Medicine 2011; 364(3):248-54

\section{P49 TUBERCULOSIS IN BIRMINGHAM IS SEASONAL}

doi:10.1136/thoraxjnl-2012-202678.190

GCKW Koh, G Hawthorne, H Kunst, M Dedicoat. Heartlands Hospital, Birmingham, United Kingdom

Background Birmingham is a large industrial city with migrant populations from Pakistan, India, Somalia and Eritrea. Central Birmingham is highly endemic for tuberculosis (TB) with an annual

Abstract P48 Table 1 Correlation between Vitamin D levels and markers of inflammation and disease severity amongst patients presenting with tuberculosis at an inner London teaching hospital

\begin{tabular}{|c|c|c|c|c|c|c|}
\hline & & $\begin{array}{l}\text { Neutrophil count at } \\
\text { diagnosis }\end{array}$ & Platelets & ESR & CRP & Albumin \\
\hline \multirow[t]{3}{*}{ Vitamin D levels (ng/ml) } & Pearson Correlation & -0.042 & -0.084 & 0.294 & -0.076 & 0.061 \\
\hline & Sig. (2-tailed) & 0.506 & 0.185 & 0.269 & 0.361 & 0.326 \\
\hline & N & 253 & 254 & 16 & 148 & 257 \\
\hline \multirow[t]{3}{*}{ Neutrophil count at diagnosis } & Pearson Correlation & & $0.363^{* *}$ & $0.221^{* * *}$ & $0.311^{* * *}$ & $-0.166^{* *}$ \\
\hline & Sig. (2-tailed) & & 0.000 & 0.001 & 0.000 & 0.000 \\
\hline & N & & 1252 & 219 & 811 & 1237 \\
\hline \multirow[t]{3}{*}{ Platelets } & Pearson Correlation & & & $0.183^{* *}$ & $0.100^{* *}$ & -0.001 \\
\hline & Sig. (2-tailed) & & & 0.006 & 0.004 & 0.963 \\
\hline & N & & & 221 & 813 & 1240 \\
\hline \multirow[t]{3}{*}{ ESR } & Pearson Correlation & & & & $0.514^{* *}$ & $-0.522^{* *}$ \\
\hline & Sig. (2-tailed) & & & & 0.000 & 0.000 \\
\hline & N & & & & 134 & 220 \\
\hline \multirow[t]{3}{*}{ CRP } & Pearson Correlation & & & & & $-0.311^{* *}$ \\
\hline & Sig. (2-tailed) & & & & & 0.000 \\
\hline & $\mathrm{N}$ & & & & & 813 \\
\hline
\end{tabular}

${ }^{* *} p<0.01$ 